\title{
The Effect of Force Feedback on Video Gamers' Performance
}

\author{
포스 피드백이 비디오 게이머들의 게임결과에 미치는 영향
}

Wooseob Jeong (정우섭)*

\begin{abstract}
The purpose of this study is to examine the effect of force feedback on video gamers' performance with two different types of game controllers, and to verify users' consistency on their perceptions of force feedback effect and their actual performances in video games. 42 qualified players' records on a driving video game were analyzed in this study. This study shows 1) the force feedback effect in video games depends on the type of game controllers, 2) there is inconsistency between gamers' perception on the force feedback effect and their actual performances with the force feedback effect, and 3) emotional pleasure (fun factor) plays a big role in gamers' performances.

$$
\text { 초 록 }
$$

이 연구의 목적은 포스 피드백이 비디오 게이머들의 게임결과에 미치는 영향을 두 가지 게임 콘트롤러에 따라 비교하는 한편, 게이머들의 포스 피드백에 관한 인식과 실제 그들의 게임결과가 일치하는지를 밝혀내고자 하는 것이다. 42 명의 게이머들이 자동차 경주 비디오 게임에 참여하였고 그들의 게임결과를 변수들에 따라 분석하였다. 분석결과, 1) 포스 피드백이 비디오 게임에 미치는 영향은 콘트롤러의 종류에 따라 다르고, 2) 게이머들의 포스 피드백에 대한 인식과 실제 그들의 게임결과는 항상 일치하지는 않으며, 3) 흥미 요소가 게이머들의 게임결과에 큰 영향을 미침을 확인할 수 있었다.

키워드: Force Feedback, Video Game, Controller, Game Interface, User Perception 포스 피드백, 비디오 게임, 콘트롤러, 게임 인터페이스, 사용자 인식
\end{abstract}

* Interim Dean, Associate Professor School of Information Studies University of Wisconsin - Milwaukee (wjj8612@uwm.edu)

논문접수일자 : 2013년 11월 13일 논문심사일자 : 2013년 11월 26일 게재확정일자 : 2013년 12월 11일 한국비블리아학회지, 24(4): 91-98, 2013. [http://dx.doi.org/10.14699/kbiblia.2013.24.4.091] 


\section{Introduction}

Video games have become a part of many young people's lives. The impact of the video games on young people's mind has been debated and James Paul Gee's recent book even says playing video games can teach some valuable mental skill to young players (Gee 2004). Now not only kids, but also many adults are playing video games. Average ages of video game players are late $20 \mathrm{~s}$ or early $30 \mathrm{~s}$ and there is no difference between genders (Norman 2004). In recent years, force feedback game pads or joy sticks are added for presumably increasing excitement while playing video games. However, whether the addition of force feedback effect to video games is really enhancing players' performance or their enjoyments is still questionable. It appears that many players still enjoy video games without force feedback, at least feel indifferent, even without sound. The purpose of this study is to examine the effect of force feedback on video gamers' performance with two different types of game controllers, and to verify users' consistency on their perceptions of force feedback effect and their actual performances in video games. It is to examine whether force feedback effect is complementary to or interfering with other modes which are available already in video games, in terms of gamers' performances.

\section{Literature Review}

Choi and others (2004) provided an overview on development of force feedback devices for PC-game, but very few studies can be found specifically on force feedback in video games. However, many studies have been done about force feedback in other areas. Researchers have developed various haptic input/output devices and software, such as the frequently used MIT's Phantom haptic interface (Salisbury and Srinivasan 1997) and others (Fritz and Barner 1999; Haanpaa and Roston 1997; Pai and Reisell 1997). Along with those developments, a number of studies tried to apply haptic displays in real world computing, such as a force feedback Braille system (Ramstein 1996; Jeong 2005), and force feedback X-windows system (Miller and Zeleznik 1999).

\subsection{User-based Experiment}

Since haptic is a relatively new research area, there have been not many studies with real subjects, but the number is growing. Gillespie and others (1998) tested their "virtual teacher" with 24 participants, and found that most participants profited from it. Klatzky and others (1993), through their experiments on haptic exploration, found that touch occurred frequently, and was initiated faster for objects' material judgment tasks, while touch is much less used for objects' shape judgment tasks. Langrana and others (1997) tested the Rutgers Master II with 32 subjects to find that the experimental group with force feedback training had slightly better performance than the control group. Colwell and others (1998) tested Impulse Engine 300 with 22 subjects to find that a haptic interface has considerable poten- 
tial for blind computer users. Rosenberg (1994) experimented with 20 subjects to find that a delay as high as $100 \mathrm{~ms}$ can exist between the presentation of haptic and audio sensations in display of a virtual rigid surface (wall) before users notice any perceptual distortion. Jeong (2001) tested ordering tasks in auditory and haptic displays with 23 subjects and found that subjects performed better with haptic only displays than with auditory only displays or with auditory/haptic combined displays. Jeong and Gluck (2003) applied haptic display to geographic information system and tested with 51 subjects to confirm the possibility of using haptic display complementing visual display.

Emery and others (2003) tested multimodal interface including haptic with 29 older adults to find the all participants performed well under auditory-haptic bimodal feedback. Jacko and others (2003) tested multimodal interface with 29 normal vision older adults and 30 visually impaired older adults to find that for some cases, non-visual (auditory or haptic) feedback forms demonstrated significant performance gains over the visual feedback form. Jeong and others (2004) proposed the interactive system which combines an immersive virtual environment with human-scale haptic interface.

\subsection{Multimodality and Cognitive Load}

Adding force feedback effect is a way of multimodality. Multimodality is beneficial when one mode is not enough or not available. For example, for the blind or visually impaired, vision is not available.
Even for the general population, when light is dim or nonexistent, vision is not enough. In those cases, other modes can replace or augment vision.

Theoretically speaking, cognitive load theory (Sweller 1993; Sweller 1994) and dual-coding theory (Paivio 1986) provide a framework for investigating multimodality. Cognitive load theory assumes that people possess a limited working or short-term memory, and for effective information processing, users need to reduce all unnecessary cognitive loads. Based on the fact that each mode has its own working memory, dual-coding theory states that information can be encoded in different modes each with its own working memory. According to the dual-coding theory, visually presented information is processed in visual working memory, whereas auditory information is processed in auditory working memory (Mayer and Moreno 1998). Thus, effective working memory capacity can be enlarged by using multiple channels, so the cognitive load associated with split attention can be reduced by presenting information in dual rather than unitary mode (Mousavi, Low, and Sweller 1995).

Studies show that multimodality is not always better than unimodality and the effectiveness of multimodality depends on the type or the situation of each task (Brewster et al. 1994; Francioni et al. 1991; Jeung et al. 1997; Storms 1998). Researchers emphasize complementarity of modalities rather than replacement of modes as the preferred task for multimodality. There are a number of studies on other modalities for visually impaired people (Edwards 1988; Jacobson 1998; Mynatt 1997), but few argue that vision can 
be replaced by auditory or haptic mode for the general population. Instead, many studies explored the complementary addition of haptic or auditory modes to the existing visual presentations (Kramer 1995). Meanwhile, many studies warn that merely adding another mode can make the user confused by the mutual interface between two modes (Jeung et al. 1997). In that case, the cognitive load is increased by multiple modalities.

\section{Research Design}

\subsection{Participants}

Students from classes in School of Information Studies at University of Wisconsin - Milwaukee participated in the experiment voluntarily. A pre-screening interview asked whether they were frequent video game player with more than 10 years of experience. This screening eliminates several “non-gamers," primarily non-traditional returning students. 42 qualified players' records were included in this study.

\subsection{Experimental Setting}

A PlayStation 2 game console was used with a video game titled Gran Turismo 3. Gran Turismo 3 was a relatively simple driving game not requiring so many button-actions like other sports or role playing games. In Gran Turismo 3, for every session, Arcade Mode, Single Race, and "Easy" Level were selected. Then, Swiss Alps (Area A) for the track, Rally Cars (Dirt Car) and IMPREZA Rally Car Prototype for the car, and Automatic transmission were selected.

A Dual Shock 2 game pad, which was included in PlayStation 2 game console set, and MadCatz's MC2 MicroCon Racing Weel and Pedals were used as game controller in the experiment.

\subsection{Experiment Procedure}

Participants were asked to play the video game with the given setting of Level, Track and Car Type 10 times in total. The completion time of each game was recorded. After the game session, participants were to ask to answer a post-questionnaire to confirm their reactions to the force feedback.

\subsection{Variables}

They played 6 games with the wheel and 4 games with the game pad. Since a game pad is thought to be more accustomed, fewer games with the game pad were thought to be reasonable due to the time constraint for the experiment. Each game controller had two options in terms of force feedback effect: a half with force feedback effect, and the other half without it. As a result, the following 2 by 2 matrix was formed for independent variables. The dependent variable was the completion time of each condition. To minimize a potential learning effect, each independent variable was randomly assigned by Latin Square method. 


\section{Result}

\subsection{Force feedback effect vs. controller type}

For each combination, the fastest completion time was compiled for statistical analysis with SPSS. A multivariate test showed that there is a significant interaction between two factors (force and controller type). Figure 1 shows the interaction by crossing two lines.

Force Feedback vs. Controller Type

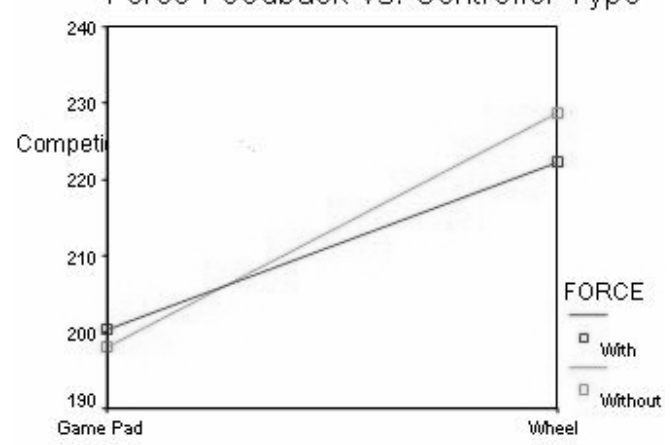

CONTROLLER

〈Figure 1〉 Force Feedback Effect vs. Controller Type

While there is little difference between "with force feedback" and "without force feedback" for performance, there is a significant difference between those two controllers. The reason for the worse performance of the wheel is thought that its rather smaller size than a real wheel caused not a good control condition. An interesting finding was that with the given game pad, the performance without force feedback is better than without it, while with the given wheel, the performance with force feedback is better. It implies that the effect of force feedback depends on other environments. The much better performance with a game pad may suggest that future automobiles might consider the change of the wheel into a pad-like controller due to its easy handling.

\subsection{Gamers' Perceptions vs. Their Performances}

Research showed that users' perceptions or preferences are not always consistent with their performances. Often even if they do not have better performance, still they like certain conditions. This phenomenon has been confirmed in this study. It was found that regardless the controller type and with or without force feedback, even if the participants thought force feedback effect helped their performances, in fact, it did not help, and vice versa. Similarly, as seen in Figure 2, participants who responded the force feedback effect was annoying had better performances, especially with the game pad, than those who said no.

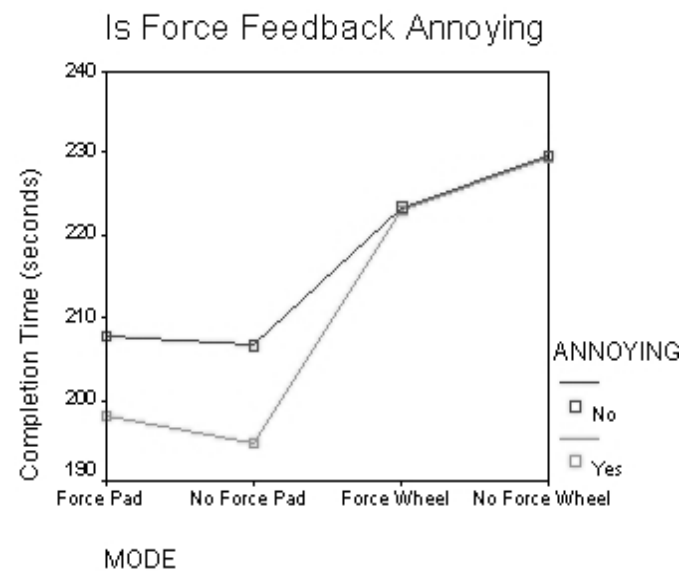

〈Figure 2〉 Is Force Feedback Annoying? 
However, force feedback seemed to give some advantage to those who thought more fun with force feedback in video game. As seen in Figure 3, the participants who replied that force feedback added more fun, had better performances than those who replied no difference.

Does Force Feedback Add More Fun

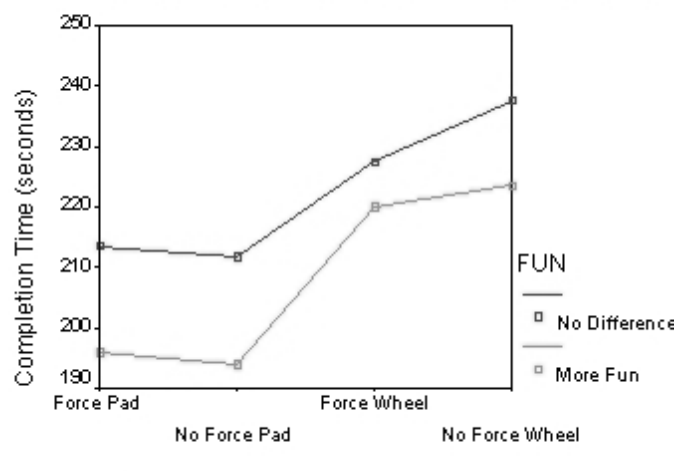

MODE

\section{〈Figure 3〉 Does Force Feedback Add More Fun?}

\section{Discussion and conclusion}

Force feedback effect does not provide any significant impact on gamers' performances regardless of the type of controllers. However, it seems that the worse controller (the wheel, in this study) could get some benefit with force feedback. It also implies that novice gamers might get advantage with force feedback in their game learning. Future studies should look at this area for clear understanding.

Gamers' perceptions are conflicting with their performances regarding force feedback effect. Those who felt annoyed by force feedback did better performance with it and those who felt getting help from force feedback did worse performance with it. This kind of inconsistency is not unusual. Jeong and Gluck (2003) reported a similar finding in their multimodal geographical information system research.

Meanwhile, the "fun" factor provided an interesting aspect of gaming. As emphasized even in Norman's interface design book (2004), emotional pleasure plays a big role in gamers' performances. It implies we can apply this emotional perspective to other information system interfaces: if the interface is pleasing, the users' productivity may go up.

This study shows 1) the force feedback effect in video games depends on the type of game controllers, and 2) there is inconsistency between gamers' perception on the force feedback effect and their actual performances with the force feedback effect. The findings provided better understanding how force feedback effect works in video games.

\section{References}

Brewster, S.A., P.C. Wright, and A.D.N. Edwards. 1994.

"The Design and Evaluation of an Auditory-

Enhanced Scrollbar." Proceedings of the
CHI'94 Conference Companion on Human

Factors in Computing Systems, 173-179.

Choi, S., H. Chang, and K. Kim. 2004. "Development 
of Force-Feedback Device for PC-game Using Vibration." Proceedings of ACE'04, June 3-5, 2004, Singapore, 325-330.

Colwell, C., H. Petrice, D. Kornbrot, A. Hardwick, and S. Furner. 1998. "Haptic Virtual Reality for Blind Computer Users." Proceeding of ASSETS'98, 92-99.

Edwards, A. D. 1988. "The Design of Auditory Interfaces for Visually Disabled Users.” Proceedings of the SIGCHI conference on Human factors in computing systems, 83-88.

Emery, V. K., P. J. Edwards, J. A. Jacko, K. P. Moloney, L. Barnard, Thitima, Kongnakorn, F. Sainfort, and I. U. Scott. 2003. "Toward Achieving Universal Usability for Older Adults through Multimodal Feedback." Proceedings of CUU'03, November 10-11, 2003, Vancouver, British Columbia, Canada, 46-53.

Francioni, J.M., L. Albright, and J.A. Jackson. 1991. "Debugging Parallel Programs Using Sound." Conference proceedings on ACM/ONR workshop on parallel and distributed debugging, 68-75.

Fritz, J.P. and K.E. Barner. 1999. "Design of a Haptic Data Visualization System for People with Visual Impairments.” IEEE Transactions on Rehabilitation Engineering, 7(3): 372-384.

Gee, J. P. 2004. What Video Games Have to Teach Us about Learning and Literacy. New York: Palgrave Macmillan.

Gillespie, R.B., M.S. O’Modhrain, P. Tang, D. Zaretzky, and C. Pham. 1998. "The Virtual Teacher." Proceedings of ASME international mechan- ical engineering congress, dynamic systems and control division. Vol.2.

Haanpaa, D.P. and G.P. Roston. 1997. "An Advanced Haptic System for Improving Man-machine Interfaces." Computer \& Graphics, 21(4): 443-449.

Jacko, J. A., I. U. Scott, F. Sainfort, L. Barnard, P. J. Edwards, V. K. Emery, T. Kongnakorn, K. P. Moloney, and B. S. Zorich. 2003. "Older Adults and Visual Impairment: What Do Exposure Times and Accuracy Tell Us about Performance Gains Associated with Multimodal Feedback?" Proceedings of CHI2003, April 5-10, 2003, Ft. Lauderdale, Florida, USA, 33-40.

Jacobson, R. D. 1998. "Cognitive Mapping without Sight: Four Preliminary Studies of Spatial Learning." Journal of Environmental Psychology, 18(3): 289-305.

Jeong, S., N. Hashimoto, and S. Makoto. 2004. “A Novel Interaction System with Force Feedback between Real and Virtual Human.” Proceedings of ACE'04, June 3-5, 2004, Singapore, 61-66. Jeong, W. 2001. "Exploratory User Study of Haptic and Auditory Display for Multimodal Geographic Information Systems." CHI'2001: Extended abstracts, 73-74.

Jeong, W. 2005. "Touchable Online Braille Generator." ASSETS 2005, 188-189.

Jeong, W. and M. Gluck. 2003. "Multimodal Geographic Information Systems: Adding Haptic and Auditory Display." Journal of the American Society for Information Science and Technology, 54(3): 229-242. 
Jeung, H., P. Chandler, and J. Sweller. 1997. "The Role of Visual Indicators in Dual Sensory Mode Instructions.” Educational Psychology, 17(3): 329-343.

Klatzky, R.L., S.J. Lederman, and D.E. Matula. 1993. "Haptic Exploration in the Presence of Vision." Journal of Experimental Psychology Human Perception and Performance, 19(4): 726-743.

Kramer, G. 1995. "Sound and Communication in Virtual Reality." Communication in the Age of Virtual Reality, June, 259-276.

Langrana, N., G. Burdea, J. Ladeji, and M. Dinsmore. 1997. "Human Performance Using Virtual Reality Tumor Palpation Simulation.” Computer \& Graphics, 21(4): 451-458.

Mayer, R.E. and R. Moreno. 1998. "A Split-attention Effect in Multimedia Learning, Evidence for Dual Processing Systems in Working Memory." Journal of Educational Psychology, 90(2): 312-320.

Miller, T. and R. Zeleznik. 1999. "The Design of 3D Haptic Widgets.” Symposium on Interactive $3 D$ Graphics, 97-102.

Mousavi, S.Y., R. Low, and J. Sweller. 1995. "Reducing Cognitive Load by Mixing Auditory and Visual Presentation Modes.” Journal of Educational Psychology, 87(2): 319-334.

Mynatt, E. D. 1997. “Transforming Graphical Interfaces into Auditory Interfaces for Blind Users."
Human-Computer Interaction, 12(1-2): 7-45. Norman, D. 2004. Emotional Design: Why We Love (or Hate) Everyday Things. Cambridge, M.A.: Basic Books.

Pai, D.K., and L.-M. Reissell. 1997. "Haptic Interaction with Multiresolution Image Curves." Computer \& Graphics, 21(4): 405-411.

Paivio, A. 1986. Mental Presentation, a Dual Coding Approach. Oxford, England: Oxford University Press.

Ramstein, C. 1996. "Combining Haptic and Braille Technologies, Design Issues and Pilot Study.” ASSETS '96, 37-44.

Rosenberg, L.B. 1994. 'Design of a Virtual Rigid Surface, Haptic/Audio Registration.” CHI '94, 257-258.

Salisbury, J.K. and M.A. Srinivasan. 1997. "Phantombased Haptic Interaction with Virtual Objects." IEEE Computer Graphics and Applications, 17(5): 6-10.

Storms, R. L. 1998. Auditory-Visual Cross-Modal Perception Phenomena. Doctoral Dissertation. Naval Postgraduate School, Monterey, California.

Sweller, J. 1993. "Some Cognitive Processes and Their Consequences for the Organization and Presentation of Information." Australian Journal of Psychology, 45(1): 1-8.

Sweller, J. 1994. "Cognitive Load Theory, Learning Difficulty and Instructional Design.” Learning and Instruction, 4: 295-312. 